\title{
Prediction of Compressive Strength of Self compacting Concrete with Flyash and Rice Husk Ash using Adaptive Neuro-fuzzy Inference System
}

\author{
S. S. Pathak, Dr. Sanjay Sharma, Dr. Hemant Sood \\ Research Scholar, Head of Deptt, Associate Professor \\ Civil Engineering Department \\ N.I.T.T.T.R, Chandigarh
}

\author{
Dr. R. K. Khitoliya \\ Professor and Head: Civil Engineering Department \\ Punjab Engineering College \\ Chandigarh, India
}

\begin{abstract}
Self-compacting concrete is an innovative concrete that does not require vibration for placing and compaction. It is able to flow under its own weight, completely filling formwork and achieving full compaction even in congested reinforcement without segregation and bleeding. In the present study self compacting concrete mixes were developed using blend of fly ash and rice husk ash. Fresh properties of theses mixes were tested by using standards recommended by EFNARC (European Federation for Specialist Construction Chemicals and Concrete system). Compressive strength at 28 days was obtained for these mixes. This paper presents development of Adaptive Neuro-fuzzy Inference System (ANFIS) model for predicting compressive strength of self compacting concrete using fly ash and rice husk ash. The input parameters used for model are cement, fly ash, rice husk ash and water content. Output parameter is compressive strength at 28 days. The results show that the implemented model is good at predicting compressive strength.
\end{abstract}

Keywords- Self compacting concrete; ANFIS; Flyash.

\section{INTRODUCTION}

With growing population, industrialization, urbanization and globalization, there is corresponding growth in the demand for infrastructure. During the 20th century, concrete has emerged as the material of choice for modern infrastructural needs. It has occupied a unique position among modern construction materials. It gives considerable freedom to the architect to mould structural elements to any shape. Almost all concretes rely critically on being fully compacted. Insufficient compaction dramatically lowers ultimate performance of concrete inspite of good mix design. As concrete is produced and placed at construction sites, under conditions far from ideal, it often ends up with unpleasant results [1].

Concrete that is capable of compaction under its own weight and can occupy all the spaces in the forms, which selflevels, does not segregate and does not entrap air is termed as self-compacting concrete (SCC). For concrete to be selfcompacting it should have filling ability, passing ability and resistance against segregation. Self compactability is obtained by limiting the coarse aggregate content and using lower water-powder ratio together with super plasticizers (SP). In the present study self compacting concrete is developed using blend of flyash and rice husk ash.
The artificial intelligence techniques have been used by many researchers to predict properties of concrete. M.C.Nataraja, M.A.Jayaram and C.N.Ravikumar developed a Fuzzy-Neuro model for normal concrete mix design. Model has been developed for approximate proportioning of standard concrete mixes [2]. B.K. Raghu Prasad, Hamid Eskandari and B.V. Venkatarama Reddy used artificial neural network to predict compressive strength of self compacting concrete and high performance concrete with high volume fly ash. The ANN was trained by data available in literature and validated by experimental results [3]. Mehdi Neshat, Ali Adeli, AzraMasoumi and Mehdi Sargolzae have carried out a comparative study on Adaptive Neuro-fuzzy Inference System (ANFIS) and Fuzzy Expert System Models (FIS) for concrete mix design [4]. Comparison between two systems FIS and ANFIS results showed that results of ANFIS system are better than FIS. AbdulkadirCüneytAydin, AhmetTortum and Muratyavuz developed a model for prediction of concrete elastic modulus using different models. Results of study indicated that the proposed ANFIS modeling approach outperforms the other given models in terms of prediction capability [5]. They proved that ANFIS approach is a viable tool for modeling the elastic modulus, as it results in more accurate predictions. ANFIS is one of such hybrid neuro-fuzzy inference expert systems which have been used in the present study.

Rafat Siddique, Pratibha Aggarwal and YogeshAggarwal predicted compressive strength of self-compacting concrete containing bottom ash using artificial neural network. The model developed from literature data was successfully extended to the experimental data [6]. Paresh Chandra Deka and Somanath N Diwate predicted 28-day compressive strength of Ready Mix Concrete by using soft computing techniques Artificial Neural Network (ANN) and Adaptive Neuro Fuzzy Inference System (ANFIS) modeling. ANFIS model having Gaussian membership function to predict concrete strength was found better than ANN [7].

\section{ADAPTIVE NEURO-FUZZY INFERENCE SYSTEM}

Adaptive Neuro-fuzzy Inference System (ANFIS) is a multi-layer adaptive network-based fuzzy inference system proposed by Jang. 
ANFIS as a modeling system consists of three distinct segments: i) the input parameters and membership functions, ii) the adaptive neuro-fuzzy inferencing system, iii) the output parameter and the defuzzifier. ANFIS architecture is represented in Fig.1. It consists of five layers of nodes. Out of the five layers, the first and the fourth layers consist of adaptive nodes while the second, third and fifth layers consist of fixed nodes. The circular nodes represent nodes that are fixed whereas the square nodes are nodes that have parameters to be learnt. Each of the input parameters has number of membership functions [8].

The process flows from layer 1 to layer 5. It is started by giving a number of sets of crisp values as input to be fuzzyfied in layer 1, passing through inference process in layer 2 and 3 where rules are applied, calculating output for each corresponding rules in layer 4 and then in layer 5 all outputs from layer 4 are summed up to get one final output. The main objective of the ANFIS is to determine the optimum values of the equivalent fuzzy inference system parameters by applying a learning algorithm using input-output data sets. The parameter optimization is done in such a way during training session that the error between the target and the actual output is minimized. Parameters are optimized by hybrid algorithm which combination of least square estimate and gradient descent method. The parameters to be optimized in ANFIS are the premise parameters which describe the shape of the membership functions, and the consequent parameters which describe the overall output of the system. The optimum parameters obtained are then used in testing session to calculate the prediction [9].

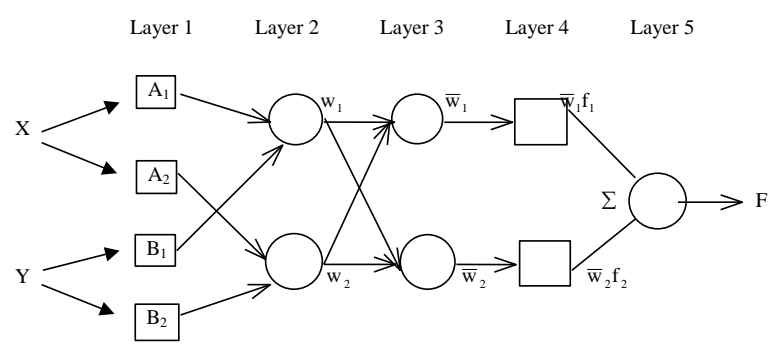

Figure 1. Anfis Structure of Two Rule Surgeno System

A Two Rule Sugeno ANFIS has rules of the form:

Rule 1: If $x$ is $A_{1}$ and $y$ is $B_{1}$, then $f_{1}=p_{1} x+q_{1} y+r_{1}$

Rule 2: If $x$ is $A_{2}$ and $y$ is $B_{2}$, then $f_{2}=p_{2} x+q_{2} y+r_{2}$.

where $\mathrm{x}$ and $\mathrm{y}$ are the inputs, Ai and Bi are the fuzzy sets, fi are the outputs within the fuzzy region specified by the fuzzy rule, $\mathrm{p}_{\mathrm{i}}, \mathrm{q}_{\mathrm{i}}$ and $\mathrm{r}_{\mathrm{i}}$ are the design parameters that are determined during the training process. In present study ANFIS model was developed using the fuzzy logic toolbox available in MATLAB software.

\section{DEVELOPMENT OF ANFIS MODEL}

Present experimental investigation was carried out to develop self compacting concrete (SCC) using blend flyash and Rice husk ash. It is important to mention that none of the test method for Self compacting concrete have yet been standardized and included in Indian Standard Code for the present. European guidelines (EFNARC) for testing, covers number of parameters ranging from material selection, mixture designs and testing methods like Slump flow test, L-box test, V-funnel test, U-box test, Orimet test and GTM screen stability for determining properties of SCC in fresh state. Most of Indian researchers are following these guidelines to determine the rheological properties of SCC mixes.

In present experimentation OPC 43 grade cement, flyash from Guru Gobind singh Super Thermal Power Station, Ropar, India and Rice Husk Ash (RHA) from Punjab Industrial area are being used for experimental investigation. A poly carboxylic based ether based superplasticizerGlenium B233 has been used. Total powder content i.e. cement fly ash and rice husk ash, was kept constant at $600 \mathrm{~kg} / \mathrm{m}^{3}$. The cement content was replaced by varying proportion of flyash and Rice husk ash. Total forty nine mixes were investigated for slump flow test, V-funnel test, U box test, L-Box, Orimet test and GTM Screen stability test. These tests were carried out as per EFNARC (European Federation for Specialist Construction Chemicals and Concrete system) standards. All these mix satisfied acceptance criteria laid down by EFNARC for fresh properties of self-compacting concrete. Compressive strength at the ages of 28 days was obtained. The ANFIS model is able to predict only one output parameter though input parameters may be many in number. In present study ANFIS model is developed to predict compressive strength at the ages of 28 days

\section{A. Design of ANFIS Model}

The ANFIS MODEL is designed by loading data, generating fuzzy inference system (FIS) and training FIS.

The input parameters were cement, flyash, rice husk ash and water content in $\mathrm{kg} / \mathrm{m}^{3}$. The Output parameter was standard 28-days cube strength in $\mathrm{MPa}$. The data set having these four inputs and one target or output for 37 mixes presented in Table I was used for designing model and data set for remaining 12 mixes was used to check accuracy of prediction (Table III).

FIS was generated by loading data sets from Table I using Grid partition method. The performance of particular membership functions is good for certain data patterns. ANFIS models were generated, using different functions like triangular (trimf), trapezoidal (trapmf), generalized bellshaped (gbellmf) andgaussian curve (gaussmf) membership function by conducting trial runs. From this a membership function was selected. The number of membership functions was three per parameter.

TABLE I. TRAINING DATA

\begin{tabular}{|c|c|c|c|c|c|}
\hline $\begin{array}{c}\text { Mix } \\
\text { No }\end{array}$ & $\begin{array}{c}\text { Cement } \\
\left(\mathbf{k g} / \mathbf{m}^{\mathbf{3}}\right)\end{array}$ & $\begin{array}{c}\mathbf{F l y a s h} \\
\left(\mathbf{k g} / \mathbf{m}^{\mathbf{3}}\right)\end{array}$ & $\begin{array}{c}\mathbf{R H A} \\
\left(\mathbf{k g} / \mathbf{m}^{\mathbf{3}}\right)\end{array}$ & $\begin{array}{c}\text { Water } \\
\left(\mathbf{k g} / \mathbf{m}^{\mathbf{3}} \mathbf{)}\right.\end{array}$ & $\begin{array}{c}\text { Compressive } \\
\text { Strength } \\
(\mathbf{~ M P a})\end{array}$ \\
\hline 1 & 240 & 360 & 0 & 228.9 & 28.52 \\
\hline 2 & 240 & 342 & 18 & 229.5 & 27.95 \\
\hline 3 & 240 & 306 & 54 & 230.9 & 26.81 \\
\hline 4 & 240 & 270 & 90 & 234 & 24.24 \\
\hline 5 & 240 & 262 & 108 & 248 & 22.3 \\
\hline 6 & 300 & 300 & 0 & 218.5 & 32.24 \\
\hline 7 & 300 & 285 & 15 & 219.3 & 31.6 \\
\hline 8 & 300 & 255 & 45 & 221 & 30.31 \\
\hline 9 & 300 & 240 & 60 & 223.5 & 29.34 \\
\hline
\end{tabular}




\begin{tabular}{|c|c|c|c|c|c|}
\hline $\begin{array}{c}\text { Mix } \\
\text { No }\end{array}$ & $\begin{array}{l}\text { Cement } \\
\left(\mathbf{k g} / \mathbf{m}^{3}\right)\end{array}$ & $\begin{array}{c}\text { Flyash } \\
\left(\mathrm{kg} / \mathrm{m}^{3}\right)\end{array}$ & $\underset{\left(\mathrm{kg} / \mathrm{m}^{3}\right)}{\text { RHA }}$ & $\begin{array}{c}\text { Water } \\
\left(\mathbf{k g} / \mathbf{m}^{3}\right)\end{array}$ & $\begin{array}{c}\text { Compressive } \\
\text { Strength } \\
\text { ( MPa) }\end{array}$ \\
\hline 10 & 300 & 225 & 75 & 224.3 & 28.37 \\
\hline 11 & 300 & 210 & 90 & 225.1 & 27.4 \\
\hline 12 & 360 & 240 & 0 & 208.8 & 39.68 \\
\hline 13 & 360 & 228 & 12 & 209.8 & 38.89 \\
\hline 14 & 360 & 204 & 36 & 211.7 & 37.3 \\
\hline 15 & 360 & 180 & 60 & 216.1 & 34.92 \\
\hline 16 & 360 & 168 & 72 & 217.6 & 33.73 \\
\hline 17 & 420 & 180 & 0 & 200 & 46.38 \\
\hline 18 & 420 & 171 & 9 & 201 & 45.45 \\
\hline 19 & 420 & 153 & 27 & 203.1 & 43.6 \\
\hline 20 & 420 & 135 & 45 & 208 & 40.81 \\
\hline 21 & 420 & 126 & 54 & 209.7 & 39.42 \\
\hline 22 & 450 & 150 & 0 & 195.8 & 48.98 \\
\hline 23 & 450 & 127.5 & 22.5 & 199.1 & 46.04 \\
\hline 24 & 450 & 112.5 & 37.5 & 204.2 & 43.1 \\
\hline 25 & 450 & 105 & 45 & 205.9 & 41.63 \\
\hline 26 & 480 & 120 & 0 & 191.9 & 51.58 \\
\hline 27 & 480 & 114 & 6 & 192.9 & 50.55 \\
\hline 28 & 480 & 102 & 18 & 195.2 & 48.49 \\
\hline 29 & 480 & 96 & 24 & 198.7 & 46.94 \\
\hline 30 & 480 & 90 & 30 & 200.5 & 45.39 \\
\hline 31 & 480 & 84 & 36 & 202.4 & 43.84 \\
\hline 32 & 510 & 90 & 0 & 188.1 & 54.19 \\
\hline 33 & 510 & 85.5 & 4.5 & 189.2 & 53.11 \\
\hline 34 & 510 & 76.5 & 13.5 & 191.5 & 50.94 \\
\hline 35 & 510 & 67.5 & 22.5 & 196.9 & 47.69 \\
\hline 36 & 510 & 63 & 27 & 198.8 & 46.06 \\
\hline 37 & 600 & 0 & 0 & 178 & 65 \\
\hline
\end{tabular}

Error obtained for various member functions is presentedin Table II

TABLE II. ERROR FOR MEMBERSHIP FUNCTIONS

\begin{tabular}{|c|c|c|c|c|}
\hline $\begin{array}{c}\text { Membership } \\
\text { Function }\end{array}$ & trimf & trapmf & gbellmf & gaussmf \\
\hline Error & 0.017 & 0.881 & 0.0321 & 0.0213 \\
\hline
\end{tabular}

The present data shows minimum error levels for triangular input membership function.

Hence triangular membership function along with three parameters was used for the present study. The triangular membership functions for cement content is shown in Fig. 2

The output membership function can either be a constant membership function or a linear membership function. For the present data, constant output membership function produced minimum error. Fuzzy inference system is trained by hybrid network for 50 numbers of epochs.

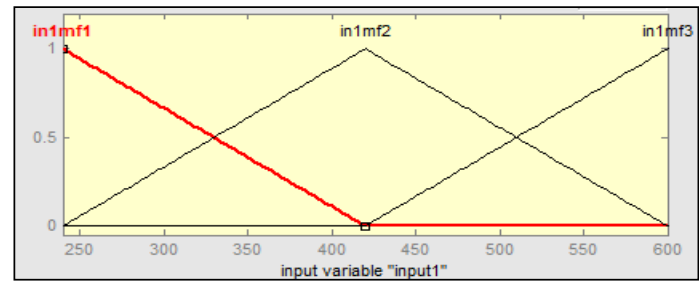

Figure 2. Membership fuction of Cement

The optimization methods train membership function parameters to emulate the training data. The hybrid optimization method is a combination of least-squares and back propagation gradient descent method. In hybrid method, model tunes with forward pass and backward pass [4]. Training error tolerance was set to zero.

The model having 81 fuzzy rules is created and Details of various parameters obtained after training are as given below

- Number of nodes

- Number of linear parameters : : 81

- Number of nonlinear parameters : 36

- Total number of parameters

- Number of training data pairs

$: 37$

- Number of fuzzy rules

- Error

: 0.01709

Structure of ANFIS model has been shown in Fig. 3.

\section{B. Testing of ANFIS Model}

Data set of four inputs for 12 mixes was used to predict compressive strength of mix in order to check accuracy of prediction of a model. Predicted compressive strength by a model and percentage error as compared to actual compressive strength is presented in Table III.

The surface viewer of compressive strength (output) with cement (input 1) and flash content (input 2) is shown in Fig. 4.

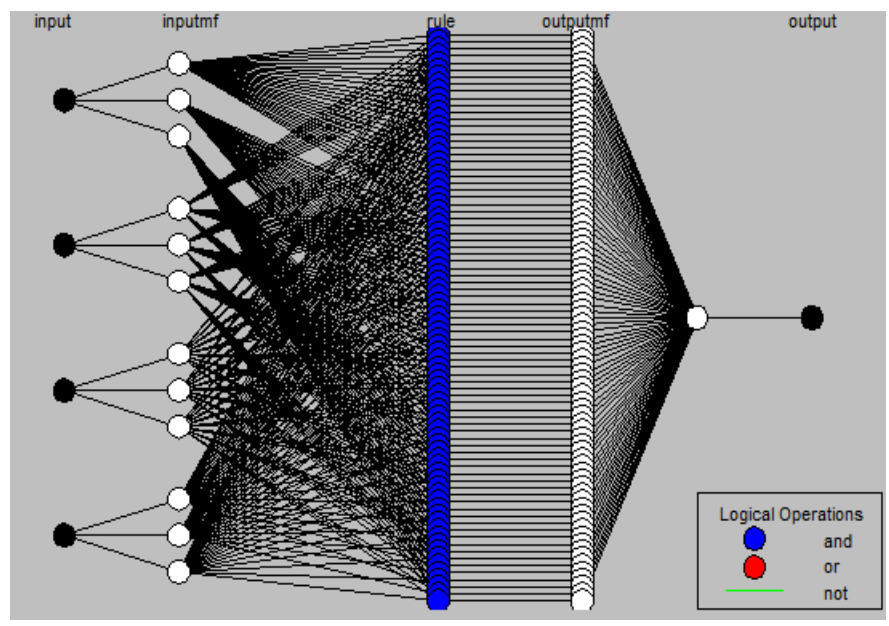

Figure 3. Structure of ANFIS Model

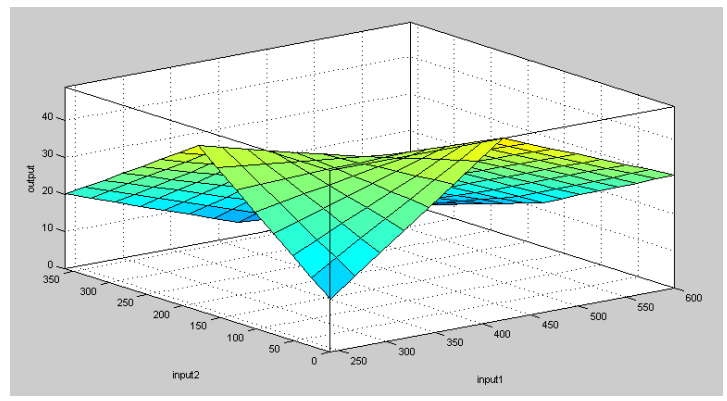

Figure 4. Surface of Compressive Strength for Cement and Flyash Content 
TABLE III. ERROR ANALYSIS IN TESTING OF ANFIS MODEL

\begin{tabular}{|c|c|c|c|c|c|c|c|}
\hline \multirow{3}{*}{$\begin{array}{c}\text { Sr. } \\
\text { No }\end{array}$} & \multicolumn{3}{|c|}{ Input Data } & \multicolumn{2}{c|}{$\begin{array}{c}\text { Compressive } \\
\text { Strength } \\
\text { (In MPa) }\end{array}$} & $\begin{array}{c}\% \\
\text { Error }\end{array}$ \\
\cline { 2 - 8 } & Cement & Flyash & RHA & Water & Predicted & Actual & \\
\hline 1 & 240 & 324 & 36 & 230.3 & 27.4 & 27.38 & -1.90 \\
\hline 2 & 240 & 288 & 72 & 233 & 25.8 & 25.1 & 5.18 \\
\hline 3 & 300 & 270 & 30 & 220.1 & 31 & 30.95 & -0.48 \\
\hline 4 & 360 & 216 & 24 & 210.7 & 38.1 & 38.09 & -0.03 \\
\hline 5 & 360 & 192 & 48 & 214.7 & 35.5 & 36.11 & -0.25 \\
\hline 6 & 420 & 162 & 18 & 202 & 44.5 & 44.52 & 0.27 \\
\hline 7 & 420 & 144 & 36 & 206.3 & 42.2 & 42.21 & 0.73 \\
\hline 8 & 450 & 135 & 15 & 198 & 47.1 & 47.02 & 0.89 \\
\hline 9 & 450 & 120 & 30 & 202.5 & 44.7 & 44.57 & -1.86 \\
\hline 10 & 480 & 108 & 12 & 194.1 & 49.6 & 49.52 & 0.65 \\
\hline 11 & 510 & 81 & 9 & 190.4 & 52.1 & 52.02 & 0.04 \\
\hline 12 & 510 & 72 & 18 & 195.1 & 49.2 & 49.31 & 0.22 \\
\hline
\end{tabular}

\section{RESULTS AND DISCUSSIONS}

The results of compressive strength predicted by the model when compared with experimental results found average error of $0.29 \%$ only (Table III).

Predicted compressive strength plotted against actual compressive strength in Fig 5 show very good coefficient of correlation 0.91.ANFIS model shows the excellent performance and is capable to predict compressive strength.

The model for prediction of compressive strength of selfcompacting concrete containing bottom ash using artificial neural network was developed by Rafat Siddique, Pratibha Aggarwal and Yogesh Aggarwal for the data from literature. Correlation coefficient of 0.91 was achieved for prediction of compressive strength at 28 days.

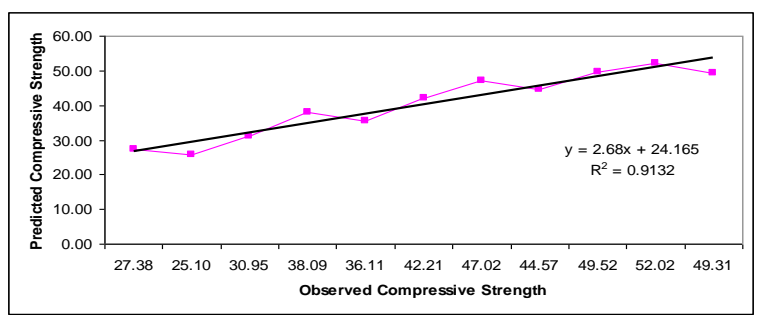

Figure 5. Correlation between Actual and Predicted Compressive Strength Fig. 5.

The overall excellent performance of model depicted in

\section{CONCLUSION}

The following conclusions can be drawn from this work:

- The ANFIS having the Triangular membership function could predict the 28-day compression strength of self compacting concrete with satisfactory performance.

- From the results obtained it can be concluded that the ANFIS models are more suitable in modeling of complex problems and save a lot of computational effort. The use of these networks will help in solving more complex problems.

\section{REFERENCES}

[1] M. Shobha, D. Harish Mohan, P. S. N. Raju,“Aggregate size and behaviour of self-compacting concrete",Proceedings of the ICE Construction Materials",Volume 159, Issue 4, 01 November 2006, pp. $147-152$

[2] G M.C.Nataraja, M.A.Jayaram, C.N.Ravikumar, "A Fuzzy-Neuro Model for Normal Concrete Mix Design", Engineering Letters,13:2, EL_13_2_8, 4 August 2006.

[3] B.K. Raghu Prasad, Hamid Eskandari,B.V.Venkatarama Reddy, "Prediction of compressive strength of SCC and HPC with highvolume fly ash using ANN", Construction and Building Materials 23 (2009), pp.117-128.

[4] Mehdi Neshat, Ali Adeli , Azra masoumi , Mehdi sargolzae, "A Comparative Study on ANFIS and Fuzzy Expert SystemModels for Concrete Mix Design",International Journal of Computer Science Issues, Online Vol. 8, Issue 3, No. 2, May 2011

[5] Abdulkadir Cüneyt Aydin, Ahmet Tortum and Muratyavuz, "Prediction of concrete elastic modulus using adaptiveneuro-fuzzy inference system”, Civil Engineering and Environmental Systems ,Vol. 23, No. 4, December 2006, pp. 295-309

[6] Rafat Siddique ,Paratibha Aggarwal, Yogesh Aggarwal, "Prediction of compressive strength of self-compacting concrete containing bottom ash using artificial neural networks",Advances in Engineering Software (2011), pp 780-786

[7] Paresh Chandra Deka and Somanath N Diwate, "Modeling Compressive Strength of Ready Mix Concrete Using Soft Computing Techniques", International Journal of Earth Sciences and Engineering, October 2011, pp. 793-796

[8] Balasubramaniam, V., P.N. Raghunath and K. Suguna, "An Adaptive Neuro-Fuzzy Inference System Based Modeling for CorrosionDamaged Reinforced HSC Beams Strengthened with External Glass Fibre Reinforced Polymer Laminates", Journal of Computer Science 8 (6): ,pp. 879-890,

[9] Vidi Bhuwana, "Rainfall Runoff Modeling by Using Adaptive-NetworkBasedFuzzy Inference System (ANFIS) - Case Study Ciliwung River ( On line Paper)"

\section{AUTHORS PROFILE}

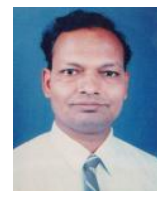

Mr. S. S. Pathak is pursuing $\mathrm{Ph}$. D program at Civil Engineering Department, National Institute of Technical Teachers Training and Research, Chandigarh under Punjab University. He has teaching experience more than 20 years. His areas of research include self compacting concrete using different mineral admixtures.

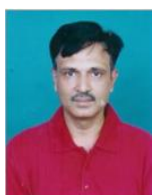

Dr. Sanjay Kumar Sharma is professor and head of Civil Engineering Department, National Institute of Technical Teachers Training and Research, Chandigarh. He has more than 25 years of experience in teaching. His areas of research includeEnvironmental Engineering, Building Repair and Rehabilitation, Irrigation and Hydraulics, Public Health Engg. and Concrete Technology.

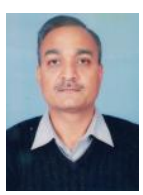

Dr. HemantSood is associate professor in Civil Engineering Department, NIITTTR, Chandigarh. He has also served in Rail India Technical and Economic Services Limited (RITES), under Ministry of Railways as Assistant Manager. $\mathrm{He}$ has more than 22 years of teaching and industrial experience. His areas of research include Highway Engineering, Pavement Design, Concrete Mix Design and Concrete Technology.

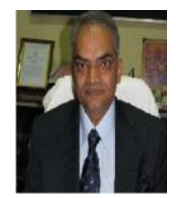

Dr. R. K. Khitoliyaobtained M. Tech (Civil Engg.) and Ph.D (Civil Engg.) from Indian Institute of Technology, Delhi. He is at present working as Professor and Head of Civil Engineering, Punjab Engineering College, Chandigarh. He is ex-director of Harcourt Butlar Technological Institute, Kanpur. His areas of interest are Geotechnicalinvestigations,Environmental Legislation, Environmental Management, Sustainable Development, Environmental Impact Assessment and Concrete Technology. 